Article

\title{
Mental Health Disease or Preventable Problem? Australian Dog Trainers' Opinions about Canine Separation Anxiety Differ with Training Style
}

\author{
Trepheena Hunter ${ }^{1, *}$, Diane van Rooy ${ }^{2}$, Michelle McArthur ${ }^{3}$, Sara Bennett ${ }^{4}$, Jonathan Tuke ${ }^{5}$ \\ and Susan Hazel ${ }^{3}$ (D) \\ 1 Wild Things Veterinary Behaviour Services, Rosanna, VIC 3084, Australia \\ 2 Dog and Cat Behaviour Consultations, Sunbury, VIC 3429, Australia; drdianevanrooy@gmail.com \\ 3 School of Animal \& Veterinary Sciences, The University of Adelaide, Roseworthy, SA 5371, Australia; \\ michelle.mcarthur@adelaide.edu.au (M.M.); susan.hazel@adelaide.edu.au (S.H.) \\ 4 Department of Clinical Sciences, College of Veterinary Medicine, North Carolina State University, Raleigh, \\ NC 27607, USA; sara_bennett@ncsu.edu \\ 5 School of Mathematical Sciences, The University of Adelaide, Adelaide, SA 5005, Australia; \\ simon.tuke@adelaide.edu.au \\ * Correspondence: trepheenahunter@wildthingsvbs.com.au
}

Received: 24 July 2020; Accepted: 10 August 2020; Published: 11 August 2020

check for updates

Simple Summary: Separation anxiety is common. Signs are seen when dogs are alone or separated from their owner, and include destructive behaviour, vocalising, restlessness, and house soiling. Many dog owners do not seek help from veterinarians but might see a trainer. The Australian dog training industry is not regulated. Trainers have a range of experience, education, and qualifications, and use a variety of techniques. We surveyed trainers' opinions about separation anxiety and found significant differences between reward-based and balanced trainers. Reward-based trainers rated involvement of a veterinarian and use of medication as more important than balanced trainers. More balanced trainers reported that medication was rarely necessary in the cases that they saw. Half the reward-based trainers believed separation anxiety was preventable compared with 95\% of balanced trainers. We conclude that opinions about separation anxiety vary between trainers using reward-based and balanced training. Trainers are not taught, expected, or legally allowed to diagnose anxiety disorders. This study found that balanced trainers were less likely to recommend involvement of veterinarians who can make a diagnosis and rule out other causes of observed behaviours. Understanding differences in trainer attitudes may help to improve communication between trainers and veterinarians to better support dogs with separation anxiety.

Abstract: Separation anxiety is common. Many dog owners do not seek help from a veterinarian but might consult a trainer. The objective of this study was to investigate Australian trainers' opinions about separation anxiety. An online survey was distributed via training organisations, resulting in 63 completed surveys. Descriptive statistics and Fisher's exact tests were applied. Respondents were grouped into reward-based $(n=41)$ and balanced $(n=22)$ trainers. Most trainers $(82.5 \%)$ used multiple methods to identify separation anxiety but only $7.9 \%$ referred to a veterinarian for diagnosis. Reward-based trainers ranked assistance from a veterinarian and owner's willingness to try medication as more important than balanced trainers $(p<0.05)$. More balanced trainers reported that medication was rarely necessary in the cases they saw: 50\% balanced compared with $4.9 \%$ reward-based trainers, with 95\% CIs of [28.2, 71.8] and [0.6, 16.5], respectively. Almost all (95.5\%) balanced trainers believed separation anxiety was preventable compared with $52.6 \%$ of reward-based trainers $(p<0.05)$. We conclude that opinions about separation anxiety varied between reward-based and balanced trainers. Trainers are not taught, expected, or legally allowed to diagnose anxiety 
disorders. This study showed that balanced trainers were less likely to recommend involvement of veterinarians who can make a diagnosis and rule out other causes of observed behaviours.

Keywords: dog; dog trainer; separation anxiety; trainer perceptions; separation related behaviour

\section{Introduction}

Dogs are a social species who have undergone selection to live alongside humans as companions for many thousands of years. They are a popular pet and approximately $40 \%$ of Australian households own a dog [1]. Dogs generally enjoy a close social bond with their owners, but they are often expected to cope with long periods of time alone while their owners are away from home. However, not all dogs cope well when their owners are away and canine separation anxiety is common, with an estimated worldwide prevalence of 13-29\% [2-7].

Separation anxiety is a collection of behaviours that occur only when dogs are left alone or separated from a significant person(s) and involves physiological and behavioural signs of distress [8]. Common signs include destructive behaviour, hypersalivation, house soiling (in a house-trained dog), vocalisation, and restlessness [9-12]. The terminology used in the scientific literature to describe this problem includes separation anxiety, separation related behaviour, separation anxiety syndrome, isolation anxiety, and attachment-related problems. No formal definitions currently exist for each term and the terms are often used interchangeably $[4,9,13]$. Trainers and pet owners commonly use diagnostic terms, such as separation anxiety, colloquially. Use of the term 'separation anxiety' by trainers can be problematic as it implies a diagnosed anxiety disorder and making a diagnosis is an "act of veterinary science", which legally should be performed by a registered veterinarian [14]. However, the aim of this study was to understand the opinions of trainers and therefore followed their colloquial use of the term separation anxiety.

While there is a substantial body of literature about canine separation anxiety, there is currently no literature reporting dog trainers' opinions. Dog training is not regulated in Australia; anyone can declare themselves a dog trainer and no formal qualification or experience is required. Dog trainers do not necessarily receive or seek training in differentiating between normal and abnormal behaviour; the focus may be on how to teach specific behaviours and cues. Some certification courses for dog trainers teach the differences between normal and abnormal behaviour while others do not; some trainers seek out further education while others do not. As such, there is variation in the depth of knowledge within the dog training industry. Although trainers should not make diagnoses and should not be expected to distinguish between normal and abnormal behaviours, they are often the first to be consulted when pet owners have a problem. Many owners either do not seek help or delay seeking help from a veterinarian $[7,15]$. Owners may have an existing relationship with a dog trainer, through puppy school classes or adult dog obedience classes, or they may seek a trainer, believing that the problem is best addressed by a trainer rather than a veterinarian. As such, trainers may be the first to provide management advice to owners. It is therefore important to understand dog trainers' understanding and management of separation anxiety.

Dog training usually involves learning via both classical and operant conditioning; these processes are explained in detail in both academic and professional texts [16-18]. There are no formal definitions of dog training styles and there are many terms used. Trainers who identify as "reward based", "positive reinforcement", "force-free" or "least invasive, minimally aversive" use predominantly positive reinforcement to teach new behaviours. They may use some negative reinforcement and negative punishment but avoid use of positive punishment. Some trainers use positive and negative reinforcement as well as positive and negative punishment. In Australia, trainers who take this approach generally refer to themselves as "balanced"; this paper therefore also uses the term "balanced" for trainers who use positive punishment as well as positive and negative reinforcement 
techniques. Trainers identifying themselves as "traditional trainers" tend to use predominantly positive punishment techniques.

There is no official registry for dog trainers. It is not possible to accurately determine the number of dog trainers practicing in Australia, nor is it possible to determine the breadth of training styles used. The number of trainers can be estimated, as some dog training organisations list their members online. This will not be accurate as dog trainers may belong to more than one organisation, they may not belong to any organisation, or they may be a member but not be listed online. The main dog training organisations in Australia are Association of Pet Dog Trainers Australia (426 members listed), Pet Professional Guild Australia (187 members listed), Delta Society (78 members listed), National Dog Trainers Federation (25 members listed) and the Australian Association of Professional Dog Trainers (9 dog training businesses listed) [19-23].

General practice veterinarians have a range of knowledge and experience in veterinary behavioural medicine that depends on the education they received during veterinary school and their choice of continuing education. Some veterinarians have extensive knowledge of behavioural medicine while others have more limited knowledge. In Australia, the term "veterinary behaviourist" refers specifically to a registered specialist in veterinary behavioural medicine. However, veterinarians who work in the field of behavioural medicine are often called "veterinary behaviourists" by trainers and the general public regardless of their qualifications. This study was aimed at trainers and therefore the term "veterinary behaviourist" was used broadly to refer to any veterinarian working in the field of veterinary behavioural medicine.

The present study aimed to investigate Australian dog trainers' opinions about the management of canine separation anxiety. We hypothesised that opinions would differ between trainers using different training methods.

\section{Materials and Methods}

\subsection{Human Ethics}

The protocols and questionnaire used in this study were approved by the University of Adelaide Human Research Ethics Committee (H-2016-012).

\subsection{Questionnaire}

Since there were no existing validated survey instruments to use, the questionnaire was developed through existing literature and discussions with dog trainers who worked with dogs with separation anxiety, and then tested by piloting the questions with the same trainers. The online questionnaire contained 31 questions over 4 sections, detailed in Appendix A. Only questions that contributed meaningfully to the aim of this study are included, and open-ended questions have also been excluded from the paper. Questions included are: Section A included 8 questions concerning demographic information; Section B contained 6 questions concerning prevalence and diagnosis; Section C included 2 questions on the perceptions of contributing factors; and Section D contained 3 questions on the management of separation anxiety. The questionnaire was available online from June to November 2016.

Section B asked trainers about the extent to which they encountered specific behaviours that may be associated with separation anxiety (see Appendix A). The behaviours included in the list were selected based on the commonly reported signs of separation anxiety [10-12,24,25]. The question did not ask respondents to explain how these behaviours were assessed, for example obtaining video footage or interviewing owners.

\subsection{Participants}

Participants were recruited initially via known dog training organisations. These organisations were sent an information sheet, a link to the online questionnaire, and a request to invite trainers to participate. Snowballing recruitment was used, with people passing on the survey using social media, 
to reach as many and as wide a population of dog trainers as possible. Inclusion criteria were that participants were "dog trainers", defined as adults who provide any service to dog owners or handlers in Australia that claims to modify a dog's behaviour. Veterinarians who did part-time dog training or provided behaviour modification exercises as part of their treatment protocol were excluded.

Respondents were classified into two groups-reward-based and balanced trainers. This grouping was based on the respondents' description of their training style. The survey included the options force-free dog training, alpha dog/dominance obedience training, balanced (both reward based/dominance obedience), or other. Those who selected "other" wrote a free-text description of their training style. The reward-based group included respondents who selected the force-free dog training option and those who wrote "positive reinforcement", "least intrusive, minimally aversive", or described their style as using positive reinforcement techniques in the free-text response. The balanced group included those who selected the balanced option and those who explained that they used positive and negative reinforcement and positive and negative punishment in their training approach. The responses of all respondents fell into these two groups.

\subsection{Statistical Analysis}

After the survey was closed, the dataset was downloaded into an Excel spreadsheet for data management. For the question about the methods used to confirm separation anxiety, an additional category "referral to a veterinarian" was created to capture a common response written in "other". The data was read into R version 4.0.2 [26] and cleaned. All Likert-type responses were treated as categorial variables. The mode was calculated for the Likert-type responses, identifying the most frequently recorded response. There were insufficient observations to perform a logistic regression with multiple predictors. Fisher's exact tests were run for each predictor. Given the number of tests performed, the $p$-values were adjusted with a false-discovery-rate (FDR) adjustment. An FDR-adjusted $p$-value of $<0.05$ was taken to indicate statistical significance. The $95 \%$ confidence interval was calculated for questions relating to the proportion of respondents in each group.

\section{Results}

\subsection{Response Rate}

One hundred and forty one surveys were submitted. Seven surveys were completed by veterinarians rather than trainers and were excluded. Seventy-one surveys were excluded due to incomplete data: 30 contained no data, 39 contained demographic answers only, and 2 included less than $75 \%$ response. The results of 63 surveys were included in the data analysis for Sections A to C. Results of 60 surveys were included in the analysis of Section D, with 3 surveys removed due to incomplete responses to Section D questions.

\subsection{Reward-Based or Balanced Trainers}

There were 22 balanced and 41 reward-based respondents. For Section $\mathrm{D}$, there were 22 balanced and 38 reward-based respondents. No respondents selected alpha dog/dominance or wrote a free-text response indicating that punishment was their primary training method.

\subsection{Demographics}

Respondents were mainly female (61 of 63 respondents) and ranged from 18 to 24 to over 65 years of age. Table 1 shows respondent demographics. 
Table 1. Demographics (absolute number and percentage) for the reward-based trainer $(n=41)$ and balanced trainer $(n=22)$ respondents.

\begin{tabular}{|c|c|c|c|}
\hline Demographic & Variable & Reward Based (\%) & Balanced (\%) \\
\hline \multirow{6}{*}{ Age (years) } & $18-24$ & $0(0.0)$ & $2(9.1)$ \\
\hline & $25-34$ & $10(24.4)$ & $4(18.2)$ \\
\hline & $35-44$ & $9(21.9)$ & $11(50.0)$ \\
\hline & $45-54$ & $11(26.8)$ & $3(13.6)$ \\
\hline & $55-64$ & $7(17.1)$ & $2(9.1)$ \\
\hline & Over 65 & $4(9.8)$ & $0(0)$ \\
\hline \multirow{3}{*}{ Education } & Year 12 or less & $2(4.9)$ & $8(36.4)$ \\
\hline & Vocational or diploma & $21(51.2)$ & $8(36.4)$ \\
\hline & Bachelor or post-graduate & $18(43.9)$ & $6(27.3)$ \\
\hline \multirow{5}{*}{ Certification } & Workshops/informal courses & $2(4.9)$ & $1(4.6)$ \\
\hline & Certificate III or IV ${ }^{1}$ & $28(68.3)$ & $11(50.0)$ \\
\hline & Certified professional dog trainer $^{2}$ & $8(19.5)$ & $5(22.7)$ \\
\hline & Diploma or Bachelor in Dog Behaviour ${ }^{2}$ & $1(2.4)$ & $1(4.6)$ \\
\hline & Other & $2(4.9)$ & $4(18.2)$ \\
\hline
\end{tabular}

${ }^{1}$ Certificate III or IV in Companion Animal Services, Dog Behaviour, or equivalent; ${ }^{2}$ or equivalent.

In the reward-based group, nearly all (95.1\%) respondents had completed vocational or tertiary education programs compared to $63.6 \%$ in the balanced group. More respondents in the balanced group listed their education level as Year 12 or less than those in the reward-based group (36.4\% balanced; $4.9 \%$ reward based). More than half the respondents listed a Certificate III or IV in Companion Animal Services/Dog Behaviour or equivalent at their highest certification in dog training. There were no statistically significant differences in age, education, or certification between the two groups, with FDR-adjusted $p$-values of $0.363,0.057$, and 0.783 , respectively.

Years worked as a trainer ranged from 0.3 to 35 years. The median number of years worked was higher for the reward-based group ( 9 years) than the balanced group (6 years); the years worked did not differ significantly between the groups (FDR-adjusted $p$-value $=1$ ). The two groups spent similar proportions of work time in puppy school classes, dog training classes, and one on one consultations (FDR-adjusted $p$-values of 1, 0.951, 0.882 respectively). Grouped together, respondents spent the highest percentage of work time doing one on one consultations ( $54.8 \%$ ) with $23.8 \%$ of time in dog training classes and $16.2 \%$ in puppy school classes.

\subsection{Prevalence and Diagnosis of Separation Anxiety}

Respondents reported seeing between 0 and $5+$ cases of separation anxiety in the past month with $1-2$ cases most frequently reported (53.6\% reward based, $40.9 \%$ balanced). The number of cases seen per month did not differ significantly between the two groups (FDR-adjusted $p$-value $=0.462$ ).

The frequency of separation anxiety signs seen in various situations is shown in Table 2 . Both groups of respondents reported that they most commonly saw dogs with separation anxiety show signs of stress or anxiety when left alone with no human or dog company. There were no significant differences between the two groups.

The signs of separation anxiety reported by trainers are shown in Table 3. There were no statistically significant differences in the reported frequency of signs of separation anxiety between the two groups. 
Table 2. Frequency of separation anxiety signs (mode and range of rank) in different situations as reported by reward-based trainer $(n=41)$ and balanced trainer $(n=22)$ respondents.

\begin{tabular}{cccc}
\hline Situation & Reward Based & Balanced & FDR-Adjusted $p$-Value \\
\hline Left alone (no human/dog company) & $5(2-5)$ & $4(2-5)$ & 0.840 \\
Owner prepares to leave & $4(1-5)$ & $3(2-5)$ & 0.366 \\
Prevented access but can see owner & $3(1-5)$ & $4(2-5)$ & 0.277 \\
In presence of owner, always trying to be in & $3(1-5)$ & $3(1-5)$ & 1 \\
proximity for physical contact & $2(1-5)$ & $3(1-4)$ & 0.913 \\
Away from home & $2(2-5)$ & $3(2-4)$ & 0.394 \\
\hline Away from owner but people/dog present &
\end{tabular}

Ranking $1-5$ based on Likert-type scales ( 1 = never; 5 = always).

Table 3. Signs of separation anxiety (mode and range of rank) reported by reward-based trainer $(n=41)$ and balanced trainer $(n=22)$ respondents.

\begin{tabular}{|c|c|c|c|}
\hline Situation & Reward Based & Balanced & FDR-Adjusted $p$-Value \\
\hline Excessive vocalisation & $4(2-5)$ & $4(3-5)$ & 0.825 \\
\hline Excessive greeting behaviours & $4(2-5)$ & $4(3-5)$ & 0.372 \\
\hline Attempts to remain close to owner at all times & $4(2-5)$ & $4(3-5)$ & 0.882 \\
\hline Escaping or escape attempts & $4(1-5)$ & $4(2-5)$ & 0.951 \\
\hline Excessive departure behaviours & $4(1-5)$ & $4(1-5)$ & 0.882 \\
\hline Excessive panting/other respiratory signs & $4(1-5)$ & $4(2-5)$ & 0.840 \\
\hline Ritualised/repetitive behaviours (pacing, circling) & $4(1-5)$ & $4(2-5)$ & 0.882 \\
\hline Changes in eating/drinking habits & $4(1-5)$ & $3(1-4)$ & 0.692 \\
\hline Destructive behaviours & $3(2-5)$ & $4(2-5)$ & 0.312 \\
\hline Hypervigilance or hyperalertness & $3(2-5)$ & $4(1-5)$ & 0.062 \\
\hline Trembling/shaking & $3(1-5)$ & $4(1-5)$ & 0.825 \\
\hline $\begin{array}{l}\text { Increased reactivity in other situations (exposure to new } \\
\text { situations, social encounters) }\end{array}$ & $3(2-5)$ & $4(1-4)$ & 0.783 \\
\hline Excessive salivation & $3(1-5)$ & $3(2-4)$ & 0.913 \\
\hline House-soiling (urination/defecation) & $3(1-5)$ & $2(1-4)$ & 0.956 \\
\hline Increased aggression behaviours (toward other dogs, humans) & $3(1-5)$ & $2(1-4)$ & 0.783 \\
\hline Increased grooming, possible self-mutilation & $3(1-5)$ & $2(1-4)$ & 0.851 \\
\hline Vomiting/diarrhoea & $2(1-5)$ & $2(1-4)$ & 1 \\
\hline Immobility/freezing or decreased activity & $2(1-5)$ & $2(1-3)$ & 1 \\
\hline
\end{tabular}

Ranking $1-5$ based on Likert-type scales ( $1=$ never; 5 = always $)$.

One respondent used only a single method to confirm suspected signs of separation anxiety while $82.5 \%$ of respondents used three or more methods. Table 4 shows the different methods used by trainers to confirm signs of separation anxiety. Only five respondents, all from the reward-based group, referred to a veterinarian for diagnosis of separation anxiety.

Table 4. Methods used to confirm suspected separation anxiety by reward-based trainer $(n=41)$ and balanced trainer $(n=22)$ respondents.

\begin{tabular}{ccccc}
\hline \multirow{2}{*}{ Method Used } & \multicolumn{2}{c}{ Reward Based } & \multicolumn{2}{c}{ Balanced } \\
\cline { 2 - 5 } & $\mathbf{\%}$ & $\mathbf{9 5 \%} \mathbf{C I}$ & $\mathbf{\%}$ & $\mathbf{9 5 \%}$ CI \\
\hline Owner reports & 85.4 & {$[70.8,94.4]$} & 90.9 & {$[70.8,98.9]$} \\
Observation of dogs in class & 36.6 & {$[22.1,53.1]$} & 45.5 & {$[24.4,67.8]$} \\
Observation of dogs at home & 82.9 & {$[67.9,92.8]$} & 90.9 & {$[70.8,98.9]$} \\
Functional assessment & 43.9 & {$[28.5,60.3]$} & 50.0 & {$[28.2,71.8]$} \\
Video footage & 68.3 & {$[51.9,81.9]$} & 54.5 & {$[32.2,75.6]$} \\
Activity monitor & 9.8 & {$[2.7,23.1]$} & 4.5 & {$[0.1,22.8]$} \\
Refer to veterinarian & 14.6 & {$[5.6,29.2]$} & 0.0 & {$[0.0,15.4]$} \\
\hline
\end{tabular}

CI: confidence interval.

Reasons cited for not referring a client to a veterinarian or veterinary behaviourist for treatment are shown in Table 5. The balanced group were more likely to select "rarely necessary for medication in the cases I see": $50.0 \%$ balanced compared with $4.9 \%$ reward-based respondents, with $95 \%$ CI of $[28.2,71.8]$ for balanced and $[0.6,16.5]$ reward based indicative of a significant difference. 
Table 5. Reasons for choosing not to refer to a veterinarian or veterinary behaviourist for treatment given by reward-based trainer $(n=41)$ and balanced trainer $(n=22)$ respondents.

\begin{tabular}{ccccc}
\hline \multirow{2}{*}{ Reason } & \multicolumn{2}{c}{ Reward Based } & \multicolumn{2}{c}{ Balanced } \\
\cline { 2 - 5 } & $\mathbf{\%}$ & $\mathbf{9 5 \%} \mathbf{C I}$ & $\mathbf{\%}$ & $\mathbf{9 5 \%}$ CI \\
\hline Medication rarely necessary in the cases I see & 4.9 & {$[0.6,16.5]$} & 50.0 & {$[28.2,71.8]$} \\
Always refer when required & 73.2 & {$[57.1,85.8]$} & 36.4 & {$[17.2,59.3]$} \\
Owner finances & 58.5 & {$[42.1,73.7]$} & 40.9 & {$[20.7,63.6]$} \\
Owner reluctant to medicate & 51.2 & {$[35.1,67.1]$} & 40.9 & {$[20.7,63.6]$} \\
Limited access & 29.3 & {$[16.1,45.5]$} & 9.1 & {$[1.1,29.2]$} \\
Veterinarian uncooperative & 14.6 & {$[5.6,29.2]$} & 13.6 & {$[2.9,34.9]$} \\
Veterinary behaviourist uncooperative & 4.9 & {$[0.6,16.5]$} & 13.6 & {$[2.9,34.9]$} \\
\hline
\end{tabular}

CI: confidence interval.

Both groups ranked "owner compliance" as important or extremely important to the success of managing separation anxiety (Table 6). The reward-based trainer respondents ranked the following higher than the balanced trainer respondents with FDR-adjusted $p$-value $<0.05$ : assistance from a veterinary behaviourist, assistance from a veterinarian, and owner's willingness to try medication.

Table 6. Factors (mode and range of rank) that affect the success of management of separation anxiety cases according to reward-based trainer $(n=41)$ and balanced trainer $(n=22)$ respondents.

\begin{tabular}{|c|c|c|c|}
\hline Factor & Reward Based & Balanced & $\begin{array}{c}\text { FDR-Adjusted } \\
p \text {-Value }\end{array}$ \\
\hline \multicolumn{4}{|l|}{ Factors ranked higher by reward-based trainers } \\
\hline Assistance from veterinarian behaviourist & $5(1-5)$ & $2(1-5)$ & 0.011 \\
\hline Assistance from veterinarian & $4(3-5)$ & $4(1-4)$ & 0.011 \\
\hline Owner's willingness to try medication & $4(2-5)$ & $2(1-5)$ & 0.011 \\
\hline \multicolumn{4}{|l|}{ No significant difference in ranking between groups } \\
\hline Owner's compliance & $5(4-5)$ & $5(4-5)$ & 0.913 \\
\hline Owner's availability for owner-dog interactions & $5(1-5)$ & $5(3-5)$ & 0.882 \\
\hline Owner's attitude to discipline & $5(1-5)$ & $4(2-5)$ & 0.825 \\
\hline Owner's level of stress & $4(2-5)$ & $5(3-5)$ & 0.882 \\
\hline Dog's stimulation when left & $4(1-5)$ & $5(3-5)$ & 0.882 \\
\hline Owner's social support (friends/family willing to help) & $4(3-5)$ & $4(2-5)$ & 0.103 \\
\hline Owners view of mental health & $4(3-5)$ & $4(2-5)$ & 0.261 \\
\hline Dog's access to inside house when left & $4(2-5)$ & $4(1-5)$ & 0.079 \\
\hline Dog's temperament & $4(1-5)$ & $4(4-5)$ & 0.462 \\
\hline Owner's financial situation & $4(3-5)$ & $3(1-5)$ & 0.051 \\
\hline Crate training & $4(1-5)$ & $4(1-5)$ & 0.390 \\
\hline Dog's age & $4(1-5)$ & $4(1-5)$ & 0.920 \\
\hline $\operatorname{Dog}^{\prime}$ s breed & $3(1-5)$ & $3(1-5)$ & 0.951 \\
\hline
\end{tabular}

Ranking $1-5$ based on Likert-type scales ( $1=$ extremely not important; $5=$ extremely important).

\subsection{Factors Contributing to Development of Separation Anxiety}

Situations that trainers associate with the onset of separation anxiety are shown in Table 7, with the highest frequency reported for "after rehoming" and "following a household change" by both groups of respondents. There were no significant differences between the two groups.

Table 7. Factors (mode and range of rank) associated with the onset of separation anxiety as reported by reward-based trainer $(n=41)$ and balanced trainer $(n=22)$ respondents.

\begin{tabular}{|c|c|c|c|}
\hline Factor & Reward Based & Balanced & FDR-Adjusted $p$-Value \\
\hline After rehoming (includes shelter, adopted dogs) & $4(1-5)$ & $4(3-5)$ & 0.312 \\
\hline Following a household change (house move, new baby) & $4(2-4)$ & $4(2-4)$ & 1 \\
\hline Following a negative event whilst left alone & $3(1-4)$ & $4(2-5)$ & 0.783 \\
\hline Old age (aging elderly dogs) & $3(1-5)$ & $3(1-4)$ & 0.851 \\
\hline Puppyhood & $2(1-4)$ & $3(1-4)$ & 0.882 \\
\hline
\end{tabular}

Ranking $1-5$ based on Likert-type scales ( $1=$ never; $5=$ always $)$. 
Ranking of factors that respondents reported would contribute to the development of separation anxiety are shown in Table 8 . There were no significant differences between the two groups.

Table 8. Factors (mode and range of rank) that reward-based trainer $(n=41)$ and balanced trainer $(n=22)$ respondents report to contribute to the development of separation anxiety.

\begin{tabular}{|c|c|c|c|}
\hline Factor & Reward Based & Balanced & FDR-Adjusted $p$-Value \\
\hline Owner's response to attention-seeking dog behaviour & $5(3-5)$ & $5(4-5)$ & 0.290 \\
\hline Owner's approach to departure/greeting rituals & $5(2-5)$ & $5(4-5)$ & 0.783 \\
\hline Owner's attitude to training/discipline & $5(1-5)$ & $5(4-5)$ & 0.882 \\
\hline Gradual exposure to separation & $5(2-5)$ & $5(2-5)$ & 1 \\
\hline Level of exercise (not enough or too much) & $4(1-5)$ & $5(3-5)$ & 0.312 \\
\hline Dog's environment when left alone & $4(3-5)$ & $5(3-5)$ & 0.905 \\
\hline Type of owner-dog interactions & $4(2-5)$ & $4(4-5)$ & 1 \\
\hline Owner's time spent with dog (always/never with dog) & $4(3-5)$ & $4(3-5)$ & 0.882 \\
\hline Dog's temperament & $4(2-5)$ & $4(2-5)$ & 1 \\
\hline Dog's genetics & $4(3-5)$ & $4(2-5)$ & 0.783 \\
\hline Number of homes & $4(2-5)$ & $4(2-5)$ & 0.676 \\
\hline Age of acquisition & $4(2-5)$ & $4(2-5)$ & 0.951 \\
\hline Source of acquisition (e.g., shelter) & $4(1-5)$ & $3(2-5)$ & 0.585 \\
\hline
\end{tabular}

Ranking $1-5$ based on Likert-type scales ( 1 = extremely not important; 5 = extremely important).

\subsection{Management of Separation Anxiety}

The importance of specific factors in the management of separation anxiety is shown in Table 9. The reward-based group ranked three factors significantly higher than the balanced group (FDR-adjusted $p$-value $<0.05$ ): referral for medication, not leaving the dog alone, and dog's access inside when alone. The reward-based group ranked owner-dog training interactions significantly lower than the balanced group (FDR-adjusted $p$-value $=0.024)$.

Table 9. The importance (mode and range of rank) of specific factors when managing separation anxiety according to reward-based trainer $(n=38)$ and balanced trainer $(n=22)$ respondents.

\begin{tabular}{|c|c|c|c|}
\hline Factor & Reward Based & Balanced & FDR-Adjusted $p$-Value \\
\hline \multicolumn{4}{|l|}{ Factors ranked higher by reward-based trainers } \\
\hline Referral for medication & $4(3-5)$ & $2,4(1-5)$ & 0.011 \\
\hline To not leave dog alone (e.g., access dog sitters) & $4(1-5)$ & $3(1-4)$ & 0.011 \\
\hline Dog's access to inside house when left alone & $4(3-5)$ & $3(1-5)$ & 0.028 \\
\hline \multicolumn{4}{|l|}{ Factors ranked higher by balanced trainers } \\
\hline Owner-dog structured interactions (e.g., training) & $4(3-5)$ & $5(3-5)$ & 0.024 \\
\hline \multicolumn{4}{|l|}{ No significant difference in ranking between groups } \\
\hline Behaviour modification-graded exposure to separation & $5(3-5)$ & $5(2-5)$ & 0.882 \\
\hline $\begin{array}{c}\text { Owner's ability to tune into dog's emotions } \\
\text { (stressed/happy) }\end{array}$ & $5(4-5)$ & $5(4-5)$ & 1 \\
\hline Encouraging dog's confidence/independence & $5(4-5)$ & $5(4-5)$ & 0.783 \\
\hline Desensitisation of dog to owner's departure cues & $5(3-5)$ & $5(4-5)$ & 0.882 \\
\hline Owner's attitude to discipline/training & $4(1-5)$ & $5(4-5)$ & 0.783 \\
\hline Owner behaviour toward attention-seeking behaviours & $4(3-5)$ & $5(4-5)$ & 0.168 \\
\hline Dog's stimulation when left & $4(3-5)$ & $4(2-5)$ & 0.372 \\
\hline Relaxation exercises (e.g., massage) & $4(2-5)$ & $4(2-5)$ & 0.693 \\
\hline Use of therapeutic agents (e.g., pheromone collar) & $4(2-5)$ & $3(2-5)$ & 0.394 \\
\hline Dog's level of exercise & $4(1-5)$ & $5(2-5)$ & 0.363 \\
\hline Owner-dog play (e.g., unstructured interactions) & $3(3-5)$ & $4(3-5)$ & 0.676 \\
\hline Increase predictability of routines & $3(1-5)$ & $3(1-5)$ & 1 \\
\hline Decrease predictability of routines & $3(1-5)$ & $4(2-5)$ & 0.882 \\
\hline
\end{tabular}

Ranking $1-5$ based on Likert-type scales ( 1 = extremely not important; 5 = extremely important).

There was a significant difference in opinion about whether separation anxiety can be prevented: $52.6 \%$ reward-based trainers replied "yes" compared with 95.5\% of balanced trainers (FDR-adjusted $p$-value $=0.032)$. Most respondents $(84.2 \%$ reward based, $90.5 \%$ balanced $)$ reported that they could sometimes identify a puppy (less than 6 months) who may develop separation anxiety. 


\section{Discussion}

To our knowledge, this is the first survey of dog trainers' perceptions and management of canine separation anxiety. We found that trainers' views differed significantly with their style of training. Most striking was the difference in opinions about medication and involvement of veterinarians. Reward-based trainers consistently ranked use of medication and veterinarian involvement significantly higher than balanced trainer respondents. When asked how important assistance from a veterinary behaviourist was in the success of management of separation anxiety, the most frequently reported response was "extremely important" from reward-based trainers compared with "not important" from balanced trainers. Similarly, reward-based trainers rated referral for medication significantly higher than balanced trainers. This was not explained by differences in demographics, experience, or case identification, as there were no significant differences between the groups in demographic variables, years of experience as a trainer, number of cases of separation anxiety seen per month, or frequencies of signs of separation anxiety reported. Rather, there may be a different understanding of separation anxiety; reward-based trainers may be more likely to view separation anxiety as an affective disorder, or mental health problem, for the dog rather than a training issue.

The notable difference between the groups was further demonstrated by the response seen when trainers were asked why they would choose not to refer to a veterinarian or veterinary behaviourist. Half of the balanced trainers felt medication was "rarely needed in the cases they saw" compared to a small proportion (4.9\%) of reward-based trainers. Current scientific literature shows that psychotropic medications are an effective component of separation anxiety treatment, together with management strategies and behaviour modification [10,27-34]. If trainers are concerned about use of medication, it is likely that owners will be reluctant to seek veterinary treatment: pet owners are likely to be guided by their trainer's beliefs. Trainers do not necessarily have any formal education in recognising affective disorders, and it would not be appropriate to expect trainers to determine when medication may be indicated. It is therefore concerning that a number of trainers in this study felt confident to decide that medication was not indicated. This highlights two points: firstly, the importance of ongoing education for trainers on the potential for an affective basis for behaviour problems; and secondly, the need to encourage collaborative care between trainers, veterinarians, and other qualified animal behaviour professionals to most effectively support the dog and owner.

The groups differed significantly when asked whether separation anxiety was preventable: almost all balanced trainers believed it was preventable compared with half of the reward-based trainers. If separation anxiety were to be preventable, the aetiology should involve only factors that relate to management and training and not those with an affective basis. The aetiology of separation anxiety is not yet clearly defined and appears to be multifactorial, including factors beyond those related to management and training. Hyperattachment has been proposed as a contributing factor [35] but some authors argue that it is neither definitive nor necessary for diagnosing separation anxiety $[8,13]$. A recent study by de Assis et al. [9] assigned dogs with separation related problems to four clinically distinct clusters, suggesting that there may be several aetiologies for separation anxiety. Genetic links have been shown in many human psychiatric conditions [36-38] and the potential for a genetic association in canine separation anxiety has been proposed. Several candidate genes for separation anxiety have been identified and an association with separation anxiety has been demonstrated for one gene in a cohort of Golden Retrievers [39]. Several studies have examined risk factors associated with separation anxiety and the data is equivocal. Source of acquisition is associated with the prevalence of separation anxiety, with dogs acquired from shelters and pet shops showing a higher prevalence than dogs from breeders or friends $[40,41]$. The findings on sex are inconsistent, with some studies showing an increased prevalence in males [7,24], while others found no association with sex [41]. There is no consensus on predisposed breeds: some authors have reported predisposition in particular breeds [24,40,41], while others report no breed predisposition [42]. Given that the aetiology is complex, multifactorial, and incompletely understood, it is difficult to categorically conclude that separation anxiety is preventable. The striking difference between reward-based and balanced trainers in this 
study may reflect trainers' understanding of behavioural development, including the role of genetics, environment, social relationship development, external stressors, and learning [43]. The balanced trainer respondents ranked training as more important for separation anxiety management than the reward-based respondents. It is possible that the balanced trainer respondents in this study felt that the owner's behaviour and management caused separation anxiety and therefore that separation anxiety could be prevented by altering human behaviour. Further work is required to understand why trainers who use particular training techniques have a different understanding of separation anxiety. This could inform development of continuing education resources for trainers and help trainers, veterinarians, and other animal behaviour professionals to work collaboratively.

The signs of separation anxiety reported in this survey are in agreement with previous studies $[10-12,24,25,35]$. This suggests that trainers were observing the behavioural and physiological signs commonly seen with separation anxiety $[44,45]$, although respondents were not asked to describe how these behaviours and physiological signs were observed. While these signs occur in dogs with separation anxiety, they are non-specific and diagnosis involves excluding differential diagnoses [44-46]. There are many differential diagnoses including behavioural and medical conditions which may not be immediately apparent. For example, there is report of comorbidity between separation anxiety and noise phobia [47] and noise phobia may be comorbid with musculoskeletal pain [48]. A recent study also reported a high prevalence of pain in dogs seen in specialist behaviour practices [49]. Trainers reported seeing signs of distress when dogs were able to see their owners but unable to access them. While this is often observed in dogs with separation anxiety, it may also indicate other problems such as confinement distress [46]. Few respondents considered referral to a veterinarian or veterinary behaviourist for diagnosis. There may be both a lack of understanding of potential medical causes for behaviour problems and a misunderstanding of the role of a veterinarian in animal care, particularly in the area of behaviour. The Australian Veterinary Association defines "acts of veterinary science" as services which form part of the practice of veterinary surgery and medicine, which includes the diagnostic confirmation of, treatment of, and provision of management advice for infectious disease, physiological dysfunction, psychological dysfunction, and injury in animals [50]. Making a diagnosis of separation anxiety is an "act of veterinary science", which legally should be performed by a veterinarian [14]. Veterinarians have an important role, ensuring that concurrent medical conditions are either ruled out or identified and treated in order to give the best prognosis for successful treatment.

This study had several limitations including self-selected respondents and low number of male respondents. The respondents all identified as either reward-based or balanced trainers; none of the respondents identified as dominance-based, traditional, or aversive trainers. This may not accurately reflect the training community. There is no information available on the techniques used by Australian dog trainers, but it would be naïve to assume that there are no trainers using dominance-based or aversive training techniques. Trainers answered the survey questions based on their previous experience and opinions about dogs showing separation anxiety. As discussed earlier, there is a range of terminology used for the behaviours seen when dogs are alone and there are no accepted definitions for these terms. It is possible that respondents in this study understood "separation anxiety" differently. Given that the dogs that they worked with may not have received a diagnosis, it is possible that respondents were referring to dogs experiencing a range of behavioural motivations, including anxiety, hyperattachment, frustration, and boredom. Section B of the questionnaire used the term diagnosis ("Prevalence and Diagnosis"). This may have implied that it was appropriate for trainers to make a diagnosis, however the term was not used in any of the questions.

This study had a low number of respondents and high variance in the data, which prevented use of a logistic regression with multiple predictors (due to low statistical power) and some correlations may have been missed (type II error). Future studies with a larger number of respondents, including trainers who used predominantly positive punishment techniques, are recommended. The data was 
collected over a six-month period so there is a potential for missing seasonal trends in case load or presentation.

Detailed analysis of training style and trainers' knowledge of learning theory was beyond the scope of this study. There is likely to be variation in the techniques applied and the proportions of positive reinforcement and positive punishment used by the balanced trainers and, perhaps to a lesser degree, the reward-based trainers. Further investigation may offer insight into the differences observed in the present study. Future studies determining where and what trainers learn about behaviour problems, such as separation anxiety, would also inform the development and provision of evidence-based continuing education resources for dog trainers.

\section{Conclusions}

This study investigated the opinions of reward-based and balanced dog trainers about canine separation anxiety. Dog trainers from both groups reported the same signs of separation anxiety that are reported in the literature. There were several notable differences between the groups. Reward-based trainers ranked involvement of veterinarians and owners' willingness to try medication as significantly more important than the balanced group. Balanced trainers were more likely to report that medication was rarely necessary for the cases of separation anxiety that they saw and to believe that separation anxiety can be prevented. While trainers are not taught, expected, or legally allowed to make a diagnosis of separation anxiety, this study indicates that balanced trainers are less likely to recommend the involvement of a veterinarian when managing dogs with suspected separation anxiety. This has the potential to delay diagnosis and impact treatment outcome if any concurrent diagnoses are not identified. Appreciation of the differences reported in this study between reward-based and balanced trainers may be used to improve communication and teamwork between all groups working to support the mental health of dogs.

Author Contributions: Conceptualization, S.H., M.M. and T.H.; methodology, S.H. and M.M.; formal analysis, J.T., S.H., T.H. and D.v.R.; investigation, S.H., T.H. and D.v.R.; data curation, J.T. and T.H.; writing-original draft preparation, T.H.; writing - review and editing, D.v.R., M.M., J.T., S.B. and S.H.; supervision, S.H., M.M. and S.B. All authors have read and agreed to the published version of the manuscript.

Funding: This research received no external funding.

Acknowledgments: We would like to acknowledge Jasmin Peacock for her work in developing the survey; the dog trainers who took time to respond; those who facilitated recruitment of respondents; and Kirsten Barlow for early conceptual support.

Conflicts of Interest: The authors declare no conflict of interest.

\section{Appendix A Australian Dog Trainers' Perspectives and Management of Separation Anxiety in Pet Dogs Questionnaire}

Questions that were excluded from the final analysis are given in italics.

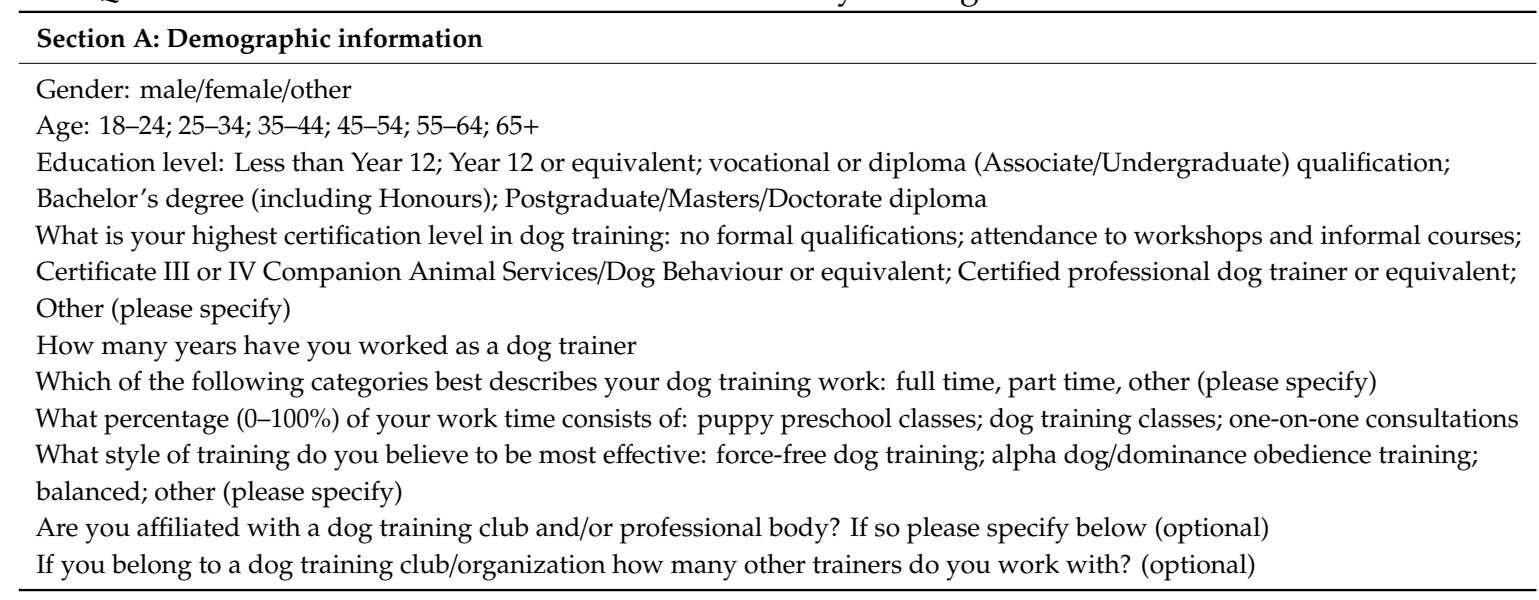




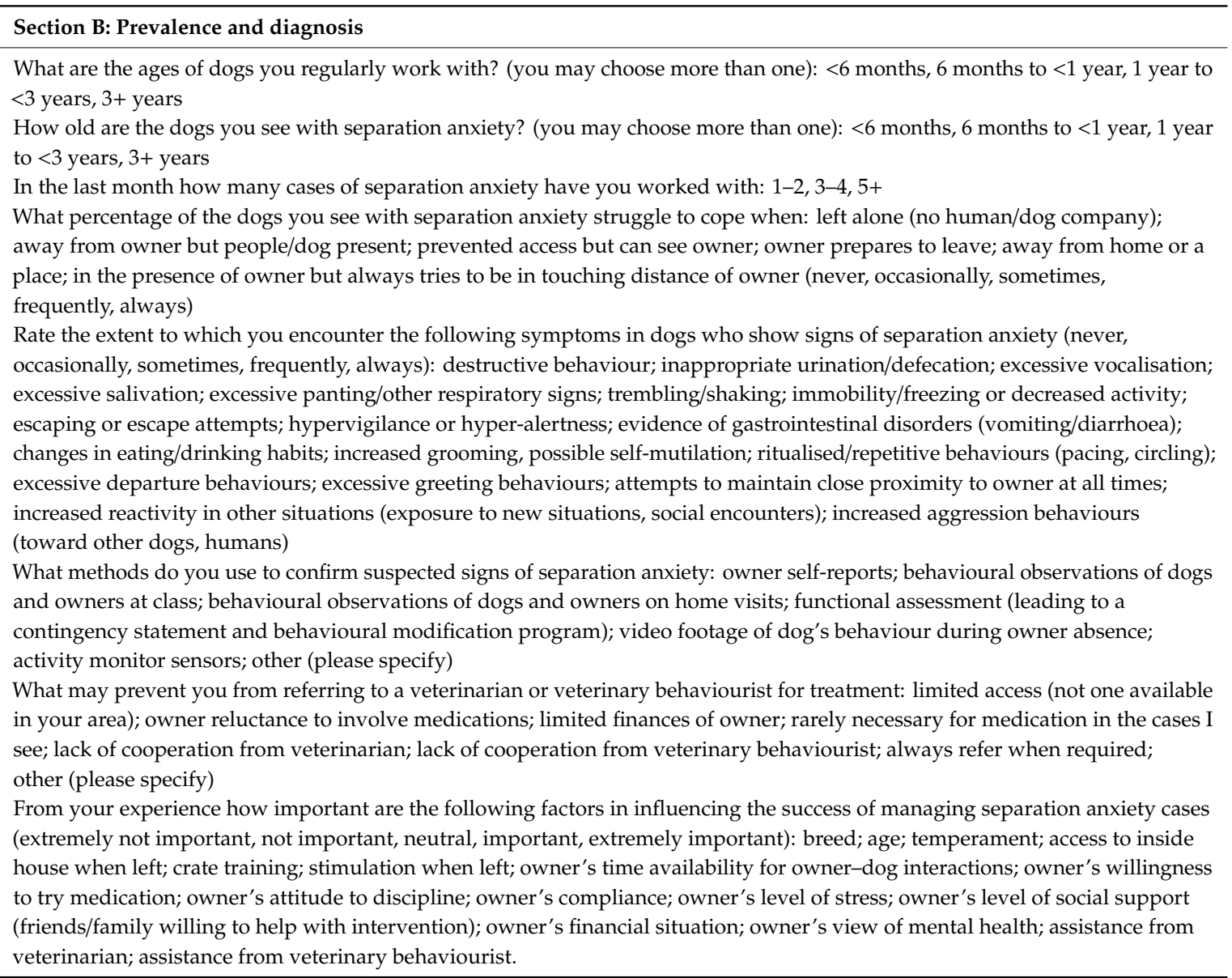

Section C: Perceptions of contributing factors and coinciding conditions

In your experience rate the extent (never, occasionally, sometimes, frequently, always) to which you see the following conditions in the dogs you work with showing signs of separation anxiety: anxiety in other situations (e.g., being outside or away from home, interactions with strangers, other dogs); fear of thunderstorms; fear of loud noises (excluding thunder storms) e.g., fireworks; medical condition (skin condition, allergies, gastrointestinal disorders); aggression (related to food/handling/strangers/other dogs); other (please specify)

Separation anxiety symptoms can emerge at different times in a dog's life. Rate the extent (never, occasionally, sometimes, frequently, always) of cases you see with the onset of separation anxiety symptoms from: puppyhood; following a negative event whilst left alone; following a household change (house move, new baby); after rehoming (includes shelter, adopted dogs); old age (aging elderly dogs)

From your experience, rate the importance of the following as potential contributing factors in the development of separation anxiety (extremely not important, not important, neutral, important, extremely important): source of acquisition (e.g., shelter); genetics; number of homes; age of acquisition; gradual exposure to separation; owner's time spent with dog (always or never with the dog); type of owner-dog interactions; owner's behaviour/responses to attention-seeking behaviour; owner's approach to departure/greeting rituals; owner's attitude to training/discipline; dog's temperament; dog's environment when left alone; level of exercise (not enough or too much); other (please specify)

In your experience from the above options provide the top three factors you believe contribute to the development of separation anxiety symptoms in pet dogs 


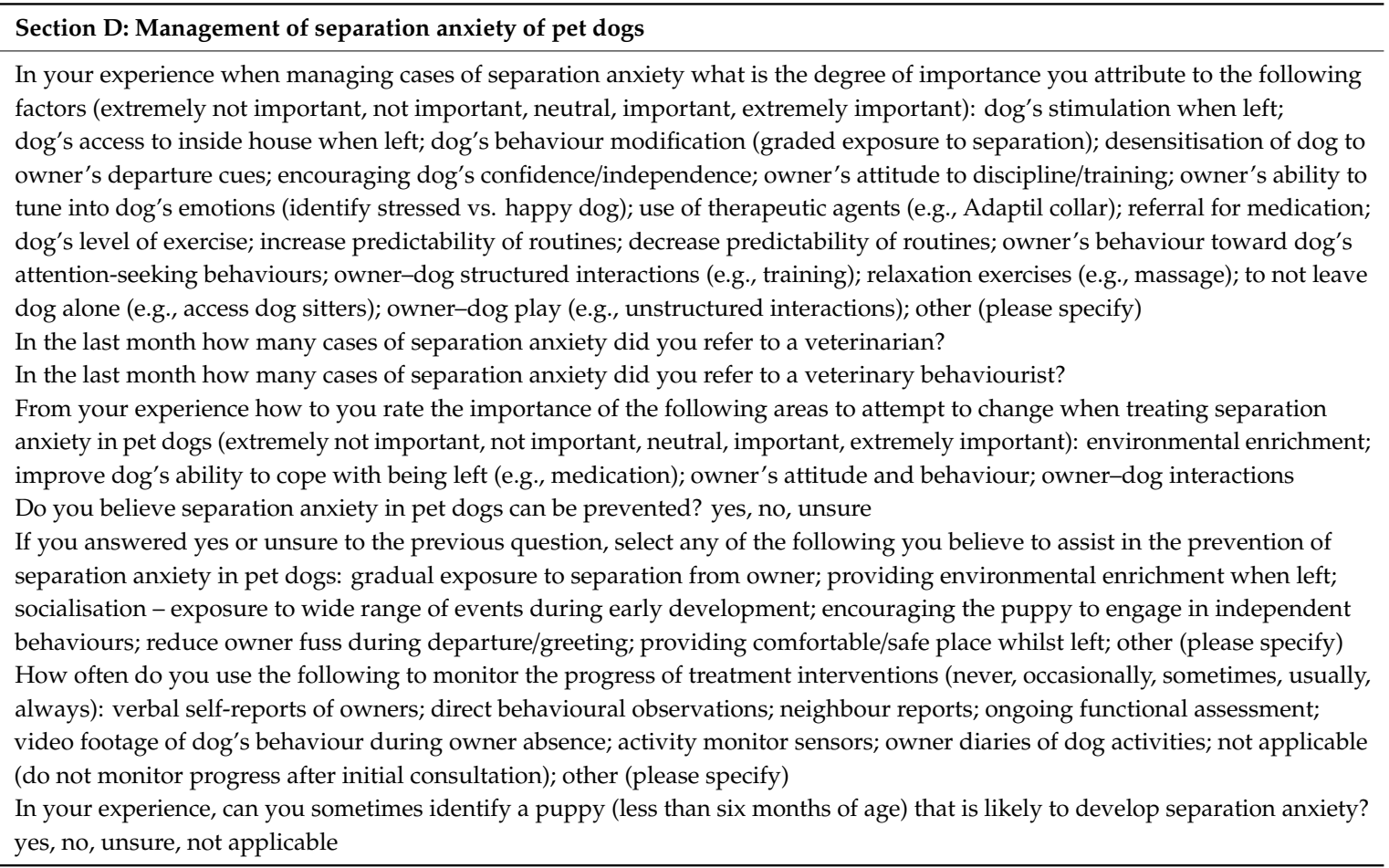

\section{References}

1. Animal Medicines Australia. Pet Ownership in Australia; Animal Medicines Australia: Barton ACT, Australia, 2019.

2. Dinwoodie, I.R.; Dwyer, B.; Zottola, V.; Gleason, D.; Dodman, N.H. Demographics and comorbidity of behavior problems in dogs. J. Vet. Behav. 2019, 32, 62-71. [CrossRef]

3. Tiira, K.; Sulkama, S.; Lohi, H. Prevalence, comorbidity, and behavioral variation in canine anxiety. J. Vet. Behav. Clin. Appl. Res. 2016, 16, 36-44. [CrossRef]

4. Blackwell, E.J.; Casey, R.A.; Bradshaw, J.W.S. Efficacy of written behavioral advice for separation-related behavior problems in dogs newly adopted from a rehoming center. J. Vet. Behav. Clin. Appl. Res. 2016, 12, 13-19. [CrossRef]

5. Gonzalez Martínez, Á.; Santamarina Pernas, G.; Diéguez Casalta, F.J.; Suárez Rey, M.L.; De la Cruz Palomino, L.F. Risk factors associated with behavioral problems in dogs. J. Vet. Behav. Clin. Appl. Res. 2011, 6, 225-231. [CrossRef]

6. Bamberger, M.; Houpt, K.A. Signalment factors, comorbidity, and trends in behavior diagnoses in dogs: 1644 Cases (1991-2001). J. Am. Vet. Med. Assoc. 2006, 229, 1591-1601. [CrossRef] [PubMed]

7. Bradshaw, J.W.S.; McPherson, J.A.; Casey, R.A.; Larter, I.S. Aetiology of separation-related behaviour in domestic dogs. Vet. Rec. 2002, 151, 43-46. [CrossRef]

8. Sherman, B.L.; Mills, D.S. Canine Anxieties and Phobias: An Update on Separation Anxiety and Noise Aversions. Vet. Clin.-Small Anim. Pract. 2008, 38, 1081-1106. [CrossRef]

9. De Assis, L.S.; Matos, R.; Pike, T.W.; Burman, O.H.P.; Mills, D.S. Developing Diagnostic Frameworks in Veterinary Behavioral Medicine: Disambiguating Separation Related Problems in Dogs. Front. Vet. Sci. 2020, 6, 499. [CrossRef]

10. Simpson, B.S.; Landsberg, G.M.; Reisner, I.R.; Ciribassi, J.J.; Horwitz, D.; Houpt, K.A.; Kroll, T.L.; Luescher, A.; Moffat, K.S.; Douglass, G.; et al. Effects of Reconcile (fluoxetine) Chewable Tablets Plus Behavior Management for Canine Separation Anxiety. Vet. Ther. 2007, 8, 18-31.

11. McCrave, E.A. Diagnostic criteria for separation anxiety in the dog. Vet. Clin. N. Am. Small Anim. Pract. 1991, 21, 247-255. [CrossRef]

12. Borchelt, P.L.; Voith, V.L. Diagnosis and treatment of separation-related behavior problems in dogs. Vet. Clin. N. Am. Small Anim. Pract. 1982, 12, 625-635. [CrossRef] 
13. Ogata, N. Separation anxiety in dogs: What progress has been made in our understanding of the most common behavioral problems in dogs? J. Vet. Behav. 2016, 16, 28-35. [CrossRef]

14. Government of South Australia South Australia Veterinary Practice Act 2003. Version 1.1. 2015. Available online: https://www.legislation.sa.gov.au/LZ/C/A/VETERINARYPRACTICEACT2003/2007.05.31/2003.41. AUTH.PDF (accessed on 14 December 2019).

15. Takeuchi, Y.; Ogata, N.; Houpt, K.A.; Scarlett, J.M. Differences in background and outcome of three behavior problems of dogs. Appl. Anim. Behav. Sci. 2001, 70, 297-308. [CrossRef]

16. Mazur, J.E. Learning and Behavior, 8th ed.; Routledge: New York, NY, USA, 2017.

17. Chance, P. Learning and Behavior, 7th ed.; Wadsworth: Belmont, TN, USA, 2014.

18. Reid, P.J. Excel-Erated Learning: Explaining in Plain English How Dogs Learn and How Best to Teach Them; James \& Kenneth Publishers: Berkeley, CA, USA, 1996.

19. Association of Pet Dog Trainers Australia. Available online: https://www.apdt.com.au/ (accessed on 14 December 2019).

20. Pet Professional Guild Australia. Available online: https://www.ppgaustralia.net.au/ (accessed on 14 December 2019).

21. Delta Institute. Available online: https://www.deltainstitute.edu.au/ (accessed on 14 December 2019).

22. National Dog Trainers Federation. Available online: https://www.ndtf.net.au/ (accessed on 14 December 2019).

23. Australian Association of Professional Dog Trainers. Available online: https://aapdt.org/ (accessed on 14 December 2019).

24. Storengen, L.M.; Boge, S.C.K.; Strøm, S.J.; Løberg, G.; Lingaas, F. A descriptive study of 215 dogs diagnosed with separation anxiety. Appl. Anim. Behav. Sci. 2014, 159, 82-89. [CrossRef]

25. Palestrini, C.; Minero, M.; Cannas, S.; Rossi, E.; Frank, D. Video analysis of dogs with separation-related behaviors. Appl. Anim. Behav. Sci. 2010, 124, 61-67. [CrossRef]

26. R Core Team. R: A language and Environment Computing, Statistical Computing; R Foundation for Statistical Computing: Vienna, Austria, 2020.

27. Cannas, S.; Frank, D.; Minero, M.; Aspesi, A.; Benedetti, R.; Palestrini, C. Video analysis of dogs suffering from anxiety when left home alone and treated with clomipramine. J. Vet. Behav. 2014, 9, 50-57. [CrossRef]

28. Pineda, S.; Anzola, B.; Olivares, A.; Ibáñez, M. Fluoxetine combined with clorazepate dipotassium and behaviour modification for treatment of anxiety-related disorders in dogs. Vet. J. 2014, 199, 387-391. [CrossRef]

29. Ogata, N.; Dodman, N.H. The use of clonidine in the treatment of fear-based behavior problems in dogs: An open trial. J. Vet. Behav. 2011, 6, 130-137. [CrossRef]

30. Ibáñez, M.; Anzola, B. Use of fluoxetine, diazepam, and behavior modification as therapy for treatment of anxiety-related disorders in dogs. J. Vet. Behav. 2009, 4, 223-229. [CrossRef]

31. Landsberg, G.M.; Melese, P.; Sherman, B.L.; Neilson, J.C.; Zimmerman, A.; Clarke, T.P. Effectiveness of fluoxetine chewable tablets in the treatment of canine separation anxiety. J. Vet. Behav. 2008, 3, 12-19. [CrossRef]

32. Gruen, M.E.; Sherman, B.L. Use of trazodone as an adjunctive agent in the treatment of canine anxiety disorders. J. Am. Vet. Med. Assoc. 2008, 233, 1902-1907. [CrossRef] [PubMed]

33. Seksel, K.; Lindeman, M.J. Use of clomipramine in treatment of obsessive-compulsive disorder, separation anxiety and noise phobia in dogs: A preliminary, clinical study. Aust. Vet. J. 2001, 79, 252-256. [CrossRef] [PubMed]

34. King, J.N.; Simpson, B.S.; Overall, K.L.; Appleby, D.; Pageat, P.; Ross, C.; Chaurand, J.P.; Heath, S.; Beata, C.; Weiss, A.B.; et al. Treatment of separation anxiety in dogs with clomipramine: Results from a prospective, randomized, double-blind, placebo-controlled, parallel-group, multicenter clinical trial. Appl. Anim. Behav. Sci. 2000, 67, 255-275. [CrossRef]

35. Appleby, D.; Pluijmakers, J. Separation anxiety in dogs: The function of homeostasis in its development and treatment. Clin. Tech. Small Anim. Pract. 2004, 19, 205-215. [CrossRef]

36. Sullivan, P.F.; Agrawal, A.; Bulik, C.M.; Andreassen, O.A.; Børglum, A.D.; Breen, G.; Cichon, S.; Edenberg, H.J.; Faraone, S.V.; Gelernter, J.; et al. Psychiatric genomics: An update and an Agenda. Am. J. Psychiatry 2018, 175, 15-27. [CrossRef] 
37. Stein, M.B.; Chen, C.Y.; Jain, S.; Jensen, K.P.; He, F.; Heeringa, S.G.; Kessler, R.C.; Maihofer, A.X.; Nock, M.K.; Ripke, S.; et al. Genetic risk variants for social anxiety. Am. J. Med. Genet. Part B Neuropsychiatr. Genet. 2017, 174, 120-131. [CrossRef]

38. Polderman, T.J.C.; Benyamin, B.; De Leeuw, C.A.; Sullivan, P.F.; Van Bochoven, A.; Visscher, P.M.; Posthuma, D. Meta-analysis of the heritability of human traits based on fifty years of twin studies. Nat. Genet. 2015, 47, 702-709. [CrossRef]

39. Van Rooy, D.; Haase, B.; Mcgreevy, P.D.; Thomson, P.C.; Wade, C.M. Evaluating candidate genes oprm1, drd2, avpr1a, and oxtr in golden retrievers with separation-related behaviors. J. Vet. Behav. Clin. Appl. Res. 2016, 16, 1-6. [CrossRef]

40. Van Rooy, D.; Thomson, P.C.; McGreevy, P.D.; Wade, C.M. Risk factors of separation-related behaviours in Australian retrievers. Appl. Anim. Behav. Sci. 2018, 209, 71-77. [CrossRef]

41. Flannigan, G.; Dodman, N.H. Risk factors and behaviors associated with separation anxiety in dogs. J. Am. Vet. Med. Assoc. 2001, 219, 460-466. [CrossRef]

42. McGreevy, P.D.; Masters, A.M. Risk factors for separation-related distress and feed-related aggression in dogs: Additional findings from a survey of Australian dog owners. Appl. Anim. Behav. Sci. 2008, 109, 320-328. [CrossRef]

43. Houpt, K.A. Domestic Animal Behavior for Veterinarians \& Animal Scientists, 6th ed.; Wiley Blackwell: Hoboken, NJ, USA, 2018.

44. Landsberg, G.M.; Hunthausen, W.; Ackerman, L. Fears, phobias, and anxiety disorders. In Behavior Problems of the Dog E Cat; Saunders Elsevier: Edinburgh, Scotland, 2013; pp. 181-210.

45. Overall, K. Abnormal Canine Behaviors and Behavioral Pathologies Not Primarily Involving Pathological Aggression. In Manual of Clinical Behavioral Medicine for Dogs and Cats; Elsevier: St Louis, MS, USA, 2013; pp. 231-311.

46. Ballantyne, K.C. Separation, Confinement, or Noises: What Is Scaring That Dog? Vet. Clin. N. Am.-Small Anim. Pract. 2018, 48, 367-386. [CrossRef] [PubMed]

47. Overall, K.L.; Dunham, A.E.; Frank, D. Frequency of nonspecific clinical signs in dogs with separation anxiety, thunderstorm phobia, and noise phobia, alone or in combination. J. Am. Vet. Med. Assoc. 2001, 219, 467-473. [CrossRef] [PubMed]

48. Fagundes, A.L.L.; Hewison, L.; McPeake, K.J.; Zulch, H.; Mills, D.S. Noise sensitivities in dogs: An exploration of signs in dogs with and without musculoskeletal pain using qualitative content analysis. Front. Vet. Sci. 2018, 5. [CrossRef] [PubMed]

49. Mills, D.S.; Demontigny-Bédard, I.; Gruen, M.; Klinck, M.P.; McPeake, K.J.; Barcelos, A.M.; Hewison, L.; Van Haevermaet, H.; Denenberg, S.; Hauser, H.; et al. Pain and problem behavior in cats and dogs. Animals 2020, 10, 318. [CrossRef]

50. Australian Veterinary Association Policies: Restricted Acts of Veterinary Science. Available online: https://www.ava.com.au/policy-advocacy/policies/professional-practices-for-veterinarians/restrictedacts-of-veterinary-science/ (accessed on 14 December 2019).

(C) 2020 by the authors. Licensee MDPI, Basel, Switzerland. This article is an open access article distributed under the terms and conditions of the Creative Commons Attribution (CC BY) license (http://creativecommons.org/licenses/by/4.0/). 